\title{
Response of atmospheric composition to COVID-19 lockdown in Paris (France)
}

Jean-Eudes Petit ( $\nabla$ jean-eudes.petit@lsce.ipsl.fr)

Laboratoire des Sciences du Climat et de l'Environnement https://orcid.org/0000-0003-1516-5927

Jean-Charles Dupont

IPSL, Ecole Polytechnique, UVSQ

Olivier Favez

INERIS

Valérie Gros

LSCE (CEA-CNRS-UVSQ)

Robert Vautard

LSCE/IPSL, CEA/CNRS/UVSQ https://orcid.org/0000-0001-5544-9903

Martial Haeffelin

IPSL, Ecole Polytechnique, CNRS

\section{Article}

Keywords: Weather Variability, Analog Methodology, Particulate Nitrate, Threshold Effect, NO Titration, Residential Wood Burning, Secondary Organic Aerosols

Posted Date: January 6th, 2021

DOI: https://doi.org/10.21203/rs.3.rs-125804/v1

License: (c) (1) This work is licensed under a Creative Commons Attribution 4.0 International License.

Read Full License 


\section{Abstract}

The worldwide COVID-19 pandemic has led to lockdowns at national scales in the Spring of 2020. Large cuts in emissions occurred, but the quantitative assessment of their role from observations is hindered by weather variability. In order to circumvent this difficulty, we developed here an innovative analog methodology and applied it to a comprehensive in-situ dataset of primary and secondary pollutants obtained at the SIRTA observatory, a suburban background site of the Paris megacity (France). We find that concentrations of primary traffic dropped by $69-76 \%$ during the lockdown period. Further, the decrease of NOx triggered a decrease of particulate nitrate (-41\%), one of the main springtime aerosol components in North-Western Europe. We reveal a threshold effect highlighting the need of substantial NOx decrease to affect particulate nitrate. At the same time, the expected ozone increase $(+21 \%)$ underlines the negative feedback of NO titration. Finally, an increase of residential wood burning sporadically compensated primary traffic, and influenced the oxidation state of secondary organic aerosols. Our results provide a quasi-comprehensive observation-based insight on mitigation policies regarding air quality in future low-carbon urban areas.

\section{Main Text}

Since early 2020, restrictions were ordained worldwide to slow down the COVID-19 contagion rate. The levels of the strictness of social distancing strategies differed significantly between countries. In some extreme cases, total lockdown was enforced during several weeks, resulting in a sudden halt of economic activities, and, as a consequence, in an unprecedented drop of emission of pollution sources. To this perspective, these lockdowns are unique opportunities to characterize an extreme end of mitigation policy scenarios and future low-carbon megacities from direct observations. Indeed, the assessments of the effects of emission cuts on air quality are almost exclusively performed by modeling. The current available literature is luxuriant about the noticeable impact of lockdowns on nitrogen oxides $\left(\mathrm{NO}_{\mathrm{x}}\right)$, ozone $\left(\mathrm{O}_{3}\right)$ and particulate matter $(\mathrm{PM})$ in various urban areas worldwide ${ }^{1,2}$. However, only a limited number of them so far have treated air quality as a whole notably by taking PM chemistry into account ${ }^{3}$. In addition, the assessment of air quality implications of large cuts in urban pollutant emissions are hampered by meteorological variability, which is one of the main drivers of air pollution temporality. Comparisons of concentrations observed during and outside the lockdown periods shall thus free themselves from differences in weather. The robustness of this assessment depends on the way meteorology is handled and on what "reference period" is chosen to compare with the "lockdown period".

We take as a case study air pollutant concentrations occurring in the Paris area, which has undergone a lockdown from March, $17^{\text {th }}$ to May $10^{\text {th }} 2020$, a period with usually high PM concentrations dominated by secondary components ${ }^{2}$. In addition, the rather flat orography of the region makes it very sensitive to air mass origins, where local emissions, such as intense vehicular traffic and residential wood burning, combine with trans-boundary polluted plumes ${ }^{3}$. Our analysis is based on a multi-year dataset (2012$2020)$ of in-situ reactive gases $\left(\mathrm{NO}_{x}, \mathrm{O}_{3}\right)$ and aerosols (chemical composition of $\mathrm{PM}$ and derived products 
from source apportionment method) at the SIRTA-ACTRIS observatory ${ }^{4}$, located $20 \mathrm{~km}$ Southwest from Paris.

\section{Compare apples with apples}

The assessment of lockdown impact on air quality leads to completely different results depending on the chosen reference period (Fig. S1). On one hand, considering the weeks preceding lockdown (PreLP) as reference leads to the determination of significant concentration increases for various regulated pollutants during the lockdown period (e.g., $+83 \%$ in $\mathrm{NO}_{x^{\prime}}+439 \%$ in $\mathrm{PM}_{1}$ ). This is mainly due to a drastic change of Western Europe meteorological conditions (from low-pressure to high-pressure system) concomitantly with the application of lockdown policy measures in France. On the other hand, considering the same weeks of previous years (e.g. 2017-2019, LP2017-2019) as reference period blindly encompasses interannual meteorological variability. As a matter of fact, April 2020 in France was the $3^{\text {rd }}$ warmest April months since 1900 , as well as exceptionally dry (-50\% of precipitation in the Paris region) and sunny ( $>+50 \%$ compared to normal). In the absence of climatological reference values, the representativeness of alternative references is a critical issue, and the major danger would be to apply methodologies unquestioningly, without verifying the strong inherent hypothesis that data are comparable. This may lead to erroneous, contradictory and counterintuitive results and can indeed be critical for semi-volatile and hygroscopic material, such as ammonium nitrate, which accounts for a significant fraction of PM during pollution episodes ${ }^{5-7}$.

That is why we developed a novel methodology, adapting for the first time the "analog weather" approach $^{8}$ to in-situ measurements. Each day of lockdown is thus compared to a group of days with similar meteorology. The analogy is based on synoptic (atmospheric circulation), regional (backtrajectories), and local (ambient temperature and relative humidity) similarities (see Methods). As our methodology is based on a day-to-day comparison, it allows a valuable evaluation of its comparability along the lockdown period: for instance, Mean Bias of $-0.17 \mathrm{~m} / \mathrm{s},-1.52^{\circ} \mathrm{C},-1.3 \mathrm{hPa}$ and $8.7 \%$ were respectively obtained for wind speed, ambient temperature, pressure and relative humidity, indicating a satisfactory analogy. Moreover, when comparing the air mass origins occurring during lockdown, our approach shows highest overall correlation $(R=0.82)$ compared to PreLP $(R=0.29)$ and LP2017-2019 $(R=0.69)$. Therefore, our analog methodology enables an efficient estimation of business as usual conditions, and provides representative and robust insights of how the lockdown induced changes of the atmospheric composition and chemistry.

We then assess the lockdown impact on a variety of atmospheric variables. Our dataset (timeseries presented in Fig. S2) is detailed in Table 1. Changes of their concentrations due to lockdown relative to 
analog days are presented in Fig. 1 and discussed in the following sections.

Table.1 Variables used in this study

\begin{tabular}{|c|c|c|}
\hline Acronym/Formula & Name & Tracer \\
\hline $\mathrm{NO}_{\mathrm{x}}$ & Nitrogen oxides & Traffic \\
\hline$B C_{f f}$ & Fossil-fuel fraction of Black Carbon & Traffic \\
\hline HOA & Hydrocarbon-like Organic Aerosols & Traffic \\
\hline $\mathrm{BC}_{\mathrm{wb}}$ & Wood burning fraction of Black Carbon & Wood burning \\
\hline BBOA & Biomass Burning Organic Aerosols & Wood burning \\
\hline OA & Organic Aerosols & - \\
\hline $\mathrm{PM}_{1}$ & Particulate Matter $(<1 \mu \mathrm{m})$ & - \\
\hline $\mathrm{NO}_{3}$ & Nitrate & Inorganic Secondary \\
\hline $\mathrm{SO}_{4}$ & Sulfate & Inorganic Secondary \\
\hline OOA & Oxygenated Organic Aerosols & Secondary Organic Aerosols \\
\hline $\mathrm{OSc}_{\mathrm{SOA}}$ & Oxidation state of SOA & \\
\hline $\mathrm{O}_{3}$ & Ozone & Secondary \\
\hline
\end{tabular}

\section{Change of atmospheric chemistry induced by $\mathrm{NO}_{x}$ abatement}

Species usually considered as markers for primary traffic emissions $\left(\mathrm{NO}_{x}, \mathrm{BC}_{\mathrm{ff}}\right.$ and $\left.\mathrm{HOA}\right)$ homogeneously exhibit a median decrease of concentrations by $69-76 \%$, despite their different chemical nature (gaseous and particulate). This expected decrease is slightly higher than what has been found in an europeanscale study ${ }^{2}$, but in the same order of magnitude than urban areas in Spain ${ }^{9}$. Our results are consistent with traffic counting data (https://dataviz.cerema.fr/trafic-routier/), which reveals a drop of about $75 \%$ in France and the Paris region. Moreover, a clear week-end effect can be observed from these data with an additional decrease from $-70 \%$ to $-90 \%$, since outdoor leisure activities were forbidden during lockdown. Interestingly, when applying a week day constraint on our analog list, we find a similar behavior for $\mathrm{NO}_{\mathrm{x}}$ 
(average of $-57 \%$ during the week, $-81 \%$ during week end), $\mathrm{BC}_{\mathrm{ff}}$ (week:-58\%, week-end: $-78 \%$ ) and $\mathrm{HOA}$ concentrations (week:-68\%, week-end: $-80 \%$ ), reinforcing the consistency of our methodology.

Nitrogen oxides play a central role within atmospheric chemistry, enabling the formation of secondary pollutants, such as tropospheric ozone and secondary organic and inorganic aerosols (SOA and SIA). We find ozone to increase by $22 \%$ (Fig. 1). This counterintuitive chemistry, due to the titration effect of NO, is well characterized ${ }^{10}$. Ozone has been also found elsewhere to rise to a similar order of magnitude $2,11,12$. The variability of absolute changes is quite important (InterQuartile Range of $22 \mu \mathrm{g} / \mathrm{m}^{3}$ ), but still inversely follows the change of $\mathrm{NO}_{\mathrm{x}}$ concentrations (Fig. 2). In addition to forecasted more frequent and intense heatwaves ${ }^{13,14}$, this lockdown is an observation-based reminder of this potential negative feedback ${ }^{15}$. However, there should be an inflection point, where an important-enough decrease of $\mathrm{NO}_{\mathrm{x}}$ directly prevents ozone from being formed. From Fig. 2, this threshold value seems to be located beyond -20 $\mu \mathrm{g} / \mathrm{m}^{3}$.

Springtime in Paris is usually associated with PM pollution episodes that are mainly triggered by particulate ammonium nitrate $\left(\mathrm{NH}_{4} \mathrm{NO}_{3}\right)$, resulting from the reaction between $\mathrm{HNO}_{3}\left(\mathrm{NO}_{\mathrm{x}}\right.$ oxidation) and ammonia $\left(\mathrm{NH}_{3}\right)$. For that matter, agricultural activities (the major source of $\mathrm{NH}_{3}$ in Western-Europe ${ }^{16}$ ) were neither stopped nor restrained. We can therefore reasonably assume business-as-usual ammonia concentrations, and since the formation regime of nitrate in Paris has previously been found to be $\mathrm{NO}_{\mathrm{x}}{ }^{-}$ limited ${ }^{17}$, a change of regime to $\mathrm{NH}_{3}$-limited is highly unlikely. On median, we find that nitrate decreases by $41 \%$, which is, as expected, linked to the decrease of $\mathrm{NO}_{x}$ (Fig. 2). The behavior of nitrate contrasts with sulphate, showing little change (-8\%), which indicates a similar influence of long-range pollution advection ${ }^{18,19}$. Interestingly, we also find a concomitant increase of the nitrogen-oxidation ratio $\left(\mathrm{NO}_{3} /\left(\mathrm{NO}_{2}+\mathrm{NO}_{3}\right), \mathrm{NOR},+53 \%\right)$, indicating a higher efficiency of $\mathrm{HNO}_{3}$ formation, which may be related to higher ozone concentrations. Nevertheless, this enhanced oxidation capacity did not compensate for the decrease of $\mathrm{NO}_{\mathrm{x}}$, suggesting the existence of a threshold effect, below which a decrease of $\mathrm{NO}_{\mathrm{x}}$ has statistically only little impact on $\mathrm{NO}_{3}$. From Fig. 2 , we locate this threshold at around $-15 \mu \mathrm{g} / \mathrm{m}^{3}$. This result indicates that in order to reduce the intensity of springtime PM pollution episodes, mitigation policies should impose substantial urban background $\mathrm{NO}_{\mathrm{x}}$ reduction.

Finally, considering secondary organic aerosols, we find a decrease of $37 \%$, which can be linked to numerous factors. The exceptional amount of sunshine during lockdown did positively influence the availability of the hydroxyl radical for the initialization of SOA formation. But $\mathrm{NO}_{\mathrm{x}}$ steps in SOA formation when reacting with peroxy radicals $\left(\mathrm{R}-\mathrm{O}_{2}\right)$, which can form less volatile products ${ }^{20}$. However, we don't find here any significant change of the oxidation state of SOA (OSc $\mathrm{SOA},-3.8 \%)$. The decrease of SOA seems to be primarily related to the decrease of $\mathrm{NO}_{\mathrm{x}}$ (Fig. 2), without any threshold effect. 


\section{The unexpected role of residential wood-burning}

Contrarily to primary traffic emissions, one striking feature of our results lies in the unexpected increase of wood burning tracers $\left(\mathrm{BC}_{\mathrm{wb}}\right.$ and $\mathrm{BBOA},+20 \%$ and $+58 \%$ respectively), despite limited absolute change (Fig.1). Converting $B C_{w b}$ to $P M_{w b}$, and $B C_{f f}$ to $P M_{f f}$ (see Methods), we also highlight that during specific days (12 out of 56), increased $\mathrm{PM}_{\mathrm{wb}}$ concentrations compensated or even exceeded the decrease of $\mathrm{PM}_{\mathrm{ff}}$ (Fig. 3a). At the same time, we notice that the mean weekly variation of wood burning changed during lockdown (Fig. 3b), with increased concentrations during the week, compared to the relatively flat variation in business-as-usual conditions (eg $+67 \%$ on Fridays). Therefore, lockdown changed both intensity and temporality of the wood burning source. This behavior can be primarily related to the stayat-home order, enhancing emissions of residential heating ${ }^{2}$. Such increased influence also mainly occurred at low wind speeds. This brings to light an unfavourable source-meteorology synergy which should be accounted for efficient mitigation policies, especially since the monotonic decreasing trend that was previously found at SIRTA (2011-2018) for traffic contrasts with the flat trend of the wood burning source ${ }^{21}$.

Wood burning is also known to be associated to substantial SOA formation, due to the reactivity of their gaseous precursors ${ }^{22}$. Although no overall change of SOA oxidation properties is reported here, we find that the temporal variability of the oxidation state of $\mathrm{SOA}\left(\mathrm{OSc}_{\mathrm{SOA}}\right)$ is inversely related to the fraction of BBOA in OA (Fig. 4). In other words, emissions from residential wood burning during lockdown unambiguously changed the chemical composition of SOA, towards less-oxidized material. Yet, SOA is a complex fraction whose understanding still remains limited because of the lack of specific tracers' measurements. A SOA-tracer based source apportionment study during Spring at SIRTA previously pointed out less oxidized SOA from wood burning ${ }^{23}$. No clear change of behavior is found for the analog dataset, which stays within the observed variability (Fig. 4). This means that lockdown has changed the variability of the wood burning source during that period of the year, which induced a change in the chemical composition of SOA, but formation pathways seem to remain similar.

The lockdown enforced during Spring 2020 in Paris corresponds to a real-life emission scenario, representing the extreme case of a quasi-total interruption of the vehicular traffic source. Up to now, no mitigation policy could have gone that far. We find from our observations that $\mathrm{NO}_{\mathrm{x}}$ reduction can be an efficient mitigation policy regarding nitrate and SOA, which account for more than half of $\mathrm{PM}_{1}$ during Spring (respectively $28.9 \%$ and $31.4 \%$ ). The Paris region has already experienced specific and temporary restrictions of vehicular traffic for air quality purposes, representing an interesting point of comparison to the radical case of a total lockdown. Reduced traffic was indeed implemented on March $17^{\text {th }}, 2014$ in Paris downtown and inner suburbs during a PM pollution episode, leading to a reduction of $\mathrm{NO}_{\mathrm{x}}$ 
concentrations of around $3-5 \mu \mathrm{g} / \mathrm{m}^{3}$ in urban background conditions. Given the results we provide here, these restrictions enforced in 2014 could not have been enough to yield a noticeable impact on nitrate and SOA.

Reducing concentrations of secondary compounds is difficult, because mitigation policies can inherently only focus on the reduction of primary pollutants. Our understanding of the complex chemistry of the urban troposphere relies firstly on a better characterization of primary precursors. To that end, additional long-term, highly time-resolved measurements of Volatile Organic Compounds would be of high interest. Yet, the efficiency of mitigation policies is largely affected by on meteorology, which can limit the impact of reduction in source emissions. Regarding these issues, our analog methodology can be an efficient tool to monitor and quantify more precisely the impact of mitigation policies.

\section{Methods}

In-situ characterization of the atmospheric composition. Measurements of aerosol composition, black carbon and $\mathrm{NO}_{x}$ have been conducted at the SIRTA facility, an observational platform integrated in the EUresearch infrastructure ACTRIS, and following corresponding Quality assurance / Quality controls guidelines. The chemical composition of major submicron non-refractory species has been monitored since the end of 2011 using an Aerosol Chemical Speciation Monitor ${ }^{24}$ (ACSM), constituting the longest ACSM dataset worldwide. Measurement principle is extensively described elsewhere ${ }^{25,26}$; the ACSM is able to provide 30-min concentrations of Organic Aerosols $(\mathrm{OA})$, Nitrate $\left(\mathrm{NO}_{3}\right)$, Sulfate $\left(\mathrm{SO}_{4}\right)$, Ammonium $\left(\mathrm{NH}_{4}\right)$ and Chloride $(\mathrm{Cl})$. Concentrations were corrected from collection efficiency ${ }^{27}(\mathrm{CE})$. The ACSM at SIRTA was regularly calibrated using 300-nm ammonium nitrate and ammonium sulfate particles to derive Ionization Efficiencies (IE), and successfully participated in the ACTRIS intercomparaison exercises $^{28,29}$.

The black carbon dataset consists of the harmonized gathering of 5-min AE31 (2011-2013) and 1-min AE33 (2014-2020) measurements at SIRTA. AE31 data were compensated using Weingartner algorithm ${ }^{30,31}$. AE33 has an online compensation approach, using the dual-spot technology ${ }^{32}$. In order to have comparable $B C$ concentrations throughout both instruments, and since no $C_{0}$ value for $A E 33$ has been recommended yet, compensated AE31 data were uncorrected from the $C_{0}$ of 2.14. Then, AE31 and $\mathrm{AE} 33$ data went through a common validation procedure ${ }^{18}$. Briefly, $\mathrm{BC}_{\lambda}$ concentrations below the Limit of Detection $\left(-100 \mathrm{ng} / \mathrm{m}^{3}\right)$ were set as invalid; for $\mathrm{BC}_{950 \mathrm{~nm}} \geq 200 \mathrm{ng} / \mathrm{m}^{3}$, the spectral dependance is calculated from the linear regression of $\ln (\lambda)$ versus $\ln \left(B_{\text {atn }}\right)$. Valid measurements are considered for an Aerosol Angström Exponent (AAE) between 0.8 and 3, and a $\mathrm{r}^{2}$ higher than 0.9.

Daily Concentrations of nitrogen monoxide $(\mathrm{NO})$ and nitrogen dioxide $\left(\mathrm{NO}_{2}\right)$ were retrieved from 1-min measurements performed with a T200UP Teledyne instrument, equipped with a blue light photolytic converter and a Nafion dryer. The instrument has been regularly calibrated with a reference standard from 
National Physics Laboratory (Teddington, $\mathrm{UK}$ ) and $\mathrm{NO}$ and $\mathrm{NO}_{2}$ concentrations have been corrected from ozone interference.

Daily ozone concentrations from 2012 to 2020 from a peri-urban station in Les Ulis, located around 10 km away from SIRTA, and operated by the lle-de-France air quality monitoring structure (Airparif, https://www.airparif.asso.fr).

Meteorological variables (wind speed and direction, temperature, relative humidity and pressure) were provided from the ReObs database ${ }^{33}$.

Source apportionment of carbonaceous aerosols. A source apportionment study of OA was carried out by Positive Matrix Factorisation ${ }^{34}$ (PMF) from January to May 2020. The analysis has been carried out seasonally (January-February and March-April-May) in order to prevent from the seasonality of the profiles of secondary factors ${ }^{35}$. Profiles of Hydrocarbon-like Organic Aerosols (HOA), Biomass Burning Organic Aerosols (BBOA) were constrained with a random a-value approach ${ }^{36}$, a third factor being left unconstrained (Oxygenated Organic Aerosol, OOA). The criteria approach of SoFi Pro ${ }^{37}$ was then used to select satisfactory solutions over 100 runs, from the R-Pearson correlation of $\mathrm{HOA}$ vs $\mathrm{BC}_{\mathrm{ff}}, \mathrm{HOA}$ vs $\mathrm{NO}_{\mathrm{x}}$ and $B B O A$ vs $B_{w b}$. Results obtained here enrich the existing timeserie ${ }^{21}$ from June 2011 to March 2018; together they form one of the longest ACSM PMF timeseries published to date. MO-OOA and LO-OOA were summed as OOA.

The oxidation properties of secondary organic aerosols were characterized by removing the contribution of primary factors to the OA matrix, as follows:

$$
f_{i}^{S O A}=\frac{m / z_{i}-\left(f_{i}^{H O A} \cdot[H O A]+f_{i}^{B B O A} \cdot[B B O A]\right)}{[O A]-([H O A]+[B B O A])}
$$

From there, $\mathrm{O}: \mathrm{C}_{\mathrm{SOA}}, \mathrm{H}: \mathrm{C}_{\mathrm{SOA}}$ and $\mathrm{OSc}_{\mathrm{SOA}}$ were calculated ${ }^{38-40}$. These equations provide only qualitative information for ACSM data, but are sufficient to characterize a change, since they are uniformily applied throughout the dataset.

Fossil-fuel and Biomass burning fractions were estimated ${ }^{41}$. Since the choice of $\alpha_{\mathrm{ff}}$ and $\alpha_{\mathrm{wb}}$ is critical and given the size of our dataset, their determination was based on the statistical hourly distribution of the AAE (Fig. S3). The value of 1.85 was chosen for $\alpha_{\mathrm{wb}}$, corresponding to a maximum frequency during the night. This value is close to the values used previously at SIRTA ${ }^{21}$, and from the recommanded value of $1.72^{42}$.

$\mathrm{PM}_{\mathrm{ff}}$ and $\mathrm{PM}_{\mathrm{wb}}$ were estimated from $\mathrm{BC}_{\mathrm{ff}}$ and $\mathrm{BC}_{\mathrm{wb}}$ concentrations, respectively, following the conversion factors of 2 and 10.3 found for SIRTA during the same season ${ }^{43}$. 
Analog. Analogues of atmospheric circulation ${ }^{8,44-47}$ have been widely used for different purposes. Here, circulation analogues are computed from daily sea-level pressure (SLP) data, to better characterize nearsurface atmospheric circulation and air masses origin, as our study covers near-surface pollutants. The SLP data is extracted from NCEP/NCAR reanalysis data ${ }^{48}$ along the historical period that covers 2012 to 2019. The SLP fields considered here have a horizontal resolution of $2.5 \times 2.5^{\circ}$ and cover a spatial domain ranging $-20^{\circ} \mathrm{W}$ to $+15^{\circ} \mathrm{E}$ in longitude and $+40^{\circ} \mathrm{N}$ to $+60^{\circ} \mathrm{N}$ in Latitude. This region is chosen because it includes atmospheric pressure patterns that influence near-surface wind ${ }^{49}$ in our area of study. The study period covers 92 days from March $1^{\text {st }}$ until May $31^{\text {st }} 2020$, while the historical period covers the same months in 2012-2019. Fifty best circulation analogues are sought for each day of the study period, using the pattern correlation as a way to measure similarity between SLP fields. The calendar distance between the day in the study period and days in the historic period is maximum 30 days. Out of 50 potential days with analogue atmospheric circulation, we keep only those with an analogue score larger than $\mathrm{C}>0.6$.

An additional filtering of the daily analog list was performed from a backtrajectory-based approach (see backtrajectory analysis), preventing the air mass origin of the synoptic analog from being significantly different from the air mass origin of the observation day. A minimum Pearson correlation coefficient of 0.2 between trajectory densities was used here. An example of satisfactory and unsatisfactory analogs is shown in Fig. S4. When correlating the overall trajectory density during lockdown and all the analog days, Pearson correlation is 0.77 (without trajectory filtering). The additionnal filter leads to an increase to 0.82 , which demonstrates the relevance of the approach.

Further, we implemented a specific constrain on local ambient temperature and Relative Humidity (RH). Indeed, both variables are key drivers of the partitionning of semi-volatile material, such as ammonium nitrate. Therefore, a satisfactory representation of local meteorological conditions by the analogs is needed in order to robustly capture and characterize any change of concentration. Over the study period, the analog performance regarding temperature and $\mathrm{RH}$ respectively ranges from $-15^{\circ} \mathrm{C}$ to $+15^{\circ} \mathrm{C}$, and from $-36 \%$ to $+64 \%$. Concretely, analogs that are much colder and wetter than the observation day may be associated to enhanced condensation of semi-volatile compounds; which would lead to a overestimation of the estimated decrease of e.g. nitrate. This specifically occurred on April $21^{\text {st }}, 22^{\text {nd }}$ and $23^{\text {rd }} 2020$. To avoid that issue, we excluded from the list the analogs having the $5 \%$ worst performance. Acceptable ranges were therefore ]-9.3, 6[ and ]-19, 35[ for temperature and $\mathrm{RH}$, respectively.

Finally, we keep for comparison only days that have at least more than 5 atmospheric circulation analogues. Analog days are satisfactorily distributed over the 2012-2020 dataset (Fig.S5), avoiding one specific year of driving business as usual conditions. 
Backtrajectory analysis. 120 -h backtrajectories ending at SIRTA $\left(49.15^{\circ} \mathrm{E}, 2.19^{\circ} \mathrm{N}\right)$ at $500 \mathrm{~m}$ a.g.I. were calculated every $6 \mathrm{~h}$ from 2012 to 2020 with the PC-based version of HYSPLIT ${ }^{50}$ using $1^{\circ} \times 1^{\circ} \mathrm{Global}$ Data Assimilation System (GDAS) files. For each day, trajectory density (log of the occurrence of trajectory endpoints) was calculated over a $0.5^{\circ} \times 0.5^{\circ}$ grid covering Western-Europe (see Fig.S3). Calculations were controlled by ZeFir ${ }^{51}$.

Sensitivity tests. The results presented in this paper primarily depend on the list of analog days that is calculated. The overall analog number is at first determined by the strictness of the correlation coefficients of atmospheric circulation and air mass origin. Selection of best analogy leads to poor statistical representativeness (Fig. S6), with a low number of analog days. It is instead preferable to remove analog days associated with worst trajectory correlation (Fig. S4). It is noteworthy that little change in the correlation coefficients (Table S1, Scenario 1-4) has little impact on the results (for all variables) presented in this manuscript (Fig. S7). This can be mainly related to the reasonable change in the number of analog days.

Similarly, the impact of subsequent filtering with temperature and relative humidity were also investigated. To this end, two additionnal scenarios were considered (S5-6, Table S1). S5 and S6 have limited impact on traffic-related variables (Fig. S7), on the contrary to wood-burning tracers and secondary compounds. This especially highlights the essential role of meteorological representativess in order to characterize the changes of secondary pollution. Indeed, when no temperature and $\mathrm{RH}$ filtering is performed (Scenario 5), highest decrease of $\mathrm{NO}_{3}$ is linked to analog days that are associated to higher $\mathrm{RH}$ (Fig. S8a) and lower temperature (Fig. S8b), which favor the partitioning of nitrate in the particulate phase. Scenario 6 has a stricter filtering than the Base one, and exhibits very good performance regarding the reconstruction of meteorological conditions (Table S2). However, we show that both scenario have very similar daily $\mathrm{NO}_{3}$ concentration change despite slight discrepancies in meteorological performance. This underlines that the thresholds used in the Base scenario are sufficient to provide robust results. 


\begin{tabular}{|c|c|c|c|c|c|}
\hline & $\begin{array}{l}\text { Synoptic } \\
\text { analog R }\end{array}$ & $\begin{array}{l}\text { Trajectory } \\
\text { analog } \mathrm{R}\end{array}$ & $\begin{array}{l}\mathrm{RH} \text { acceptability } \\
\text { range }\end{array}$ & $\begin{array}{l}T \text { acceptability } \\
\text { range }\end{array}$ & $\begin{array}{l}\text { Min. } \\
\text { Analog nb }\end{array}$ \\
\hline Base & 0.6 & 0.2 & ]-19, 35[ & ]$-9.3,6[$ & 5 \\
\hline $\begin{array}{l}\text { Scenario } \\
1\end{array}$ & 0.6 & 0.3 & ]-19, 35[ & ]$-9.3,6[$ & 5 \\
\hline $\begin{array}{l}\text { Scenario } \\
2\end{array}$ & 0.6 & 0.1 & ]-19, 35[ & ]$-9.3,6[$ & 5 \\
\hline $\begin{array}{l}\text { Scenario } \\
3\end{array}$ & 0.5 & 0.2 & ]$-19,35[$ & ]$-9.3,6[$ & 5 \\
\hline $\begin{array}{l}\text { Scenario } \\
4\end{array}$ & 0.7 & 0.2 & ]-19, 35[ & ]$-9.3,6[$ & 5 \\
\hline $\begin{array}{l}\text { Scenario } \\
5\end{array}$ & 0.6 & 0.2 & - & - & 5 \\
\hline $\begin{array}{l}\text { Scenario } \\
6\end{array}$ & 0.6 & 0.2 & ]$-19,17[$ & ]$-8,6[$ & 3 \\
\hline
\end{tabular}

Table S1. Acceptability thresholds used in different scenarios to evaluate the sensitivity of our methodology.

\begin{tabular}{|lllll|}
\hline & $\begin{array}{l}\text { RH Mean } \\
\text { Biais } \\
(\%)\end{array}$ & $\begin{array}{l}\text { Temperature Mean } \\
\text { Biais } \\
\left({ }^{\circ} \mathrm{C}\right)\end{array}$ & $\begin{array}{l}\text { Wind Speed Mean } \\
\text { Biais } \\
(\mathrm{m} / \mathrm{s})\end{array}$ & $\begin{array}{l}\text { Pressure Mean } \\
\text { Biais } \\
(\mathrm{hPa})\end{array}$ \\
\hline Base & -8.7 & +1.52 & -0.17 & -1.3 \\
\hline $\begin{array}{l}\text { Scenario } \\
5\end{array}$ & -10.5 & +2.1 & -0.14 & -0.52 \\
\hline $\begin{array}{l}\text { Scenario } \\
6\end{array}$ & -1.95 & +1.2 & -0.21 & -2.35 \\
\hline
\end{tabular}

Table S2. Performance (expressed as Mean Biais) of different scenarios to predict meteorological parameters during lockdown

\section{Data availability}

In-situ measurements are available through the EBAS database (https://ebas.nilu.no). Ozone data from Airparif are available on https://www.airparif-asso.fr 
GDAS files for backtrajectory calculation are available on https://www.arl.noaa.gov/hysplit/hysplit/

ZeFir procedure is available on https://sites.google.com/site/zefirproject/

\section{Declarations}

\section{Acknowledgments}

The authors would like to thank Jean Sciare for his implication in the start of in-situ measurements at SIRTA. Tanguy Amodeo, Vincent Crenn, Robin Aujay-Plouzeau, François Truong and Nicolas Bonnaire are acknowledged for their contribution in the monitoring of in-situ measurements. In-situ measurements at SIRTA are partially operated with the support of CNRS-INSU under the long term observation program and the French Ministry for Research under the ACTRIS-FR national research infrastructure. Additionnal support was provided from CEA and the French Ministry of the Environment.

\section{Author contributions}

J.-E.P., O.F, V.G., and J.-C.D. contributed to the availability of in-situ measurements at SIRTA. R.V. provided the list of analog days from synoptic circulation. J.-C.D. and M.H. demonstrated the feasibility of the analog method on SIRTA in-situ data. J.-E.P. performed the additional analyses. J.-E.P. wrote the paper with the assistance from all authors.

\section{Competing interests}

The authors declare no competing interests

\section{References}

1. He, G., Pan, Y. \& Tanaka, T. The short-term impacts of COVID-19 lockdown on urban air pollution in China. Nat Sustain (2020) doi:10.1038/s41893-020-0581-y.

2. Grange, S. K. et al. COVID-19 lockdowns highlight a risk of increasing ozone pollutionin European urban areas. Atmospheric Chemistry and Physics Discussions (2020) doi:10.5194/acp-2020-1171.

3. Kroll, J. H. et al. The complex chemical effects of COVID-19 shutdowns on air quality. Nat. Chem. 12, 777-779 (2020).

4. Haeffelin, M. et al. SIRTA, a ground-based atmospheric observatory for cloud and aerosol research. Annales Geophysicae 253-275 (2005). 
5. Zhang, Q. et al. Ubiquity and dominance of oxygenated species in organic aerosols in anthropogenically-influenced Northern Hemisphere midlatitudes. Geophysical Research Letters 34, (2007).

6. Huang, R.-J. et al. High secondary aerosol contribution to particulate pollution during haze events in China. Nature (2014) doi:10.1038/nature13774.

7. Beekmann, M. et al. In situ, satellite measurement and model evidence on the dominant regional contribution to fine particulate matter levels in the Paris megacity. Atmospheric Chemistry and Physics 15, 9577-9591 (2015).

8. Yiou, P. et al. Ensemble reconstruction of the atmospheric column from surface pressure using analogues. Clim Dyn 41, 1333-1344 (2013).

9. Petetin, H. et al. Meteorology-normalized impact of COVID-19 lockdown upon NO2 pollution in Spain. (2020) doi:10.5194/acp-2020-446.

10. Reis, S. et al. Road traffic emissions - predictions of future contributions to regional ozone levels in Europe. Atmospheric Environment 34, 4701-4710 (2000).

11. Sicard, P. et al. Amplified ozone pollution in cities during the COVID-19 lockdown. Science of The Total Environment 735, 139542 (2020).

12. Bao, R. \& Zhang, A. Does lockdown reduce air pollution? Evidence from 44 cities in northern China. Science of The Total Environment 731, 139052 (2020).

13. Lehner, F., Deser, C. \& Sanderson, B. M. Future risk of record-breaking summer temperatures and its mitigation. Climatic Change 146, 363-375 (2018).

14. European Commission. Joint Research Centre. Global warming and human impacts of heat and cold extremes in the EU: JRC PESETA IV project: Task 11. (Publications Office, 2020).

15. Archibald, A. T. et al. On the changes in surface ozone over the twenty-first century: sensitivity to changes in surface temperature and chemical mechanisms. Phil. Trans. R. Soc. A. 378, 20190329 (2020).

16. Fortems-Cheiney, A. et al. Unaccounted variability in $\mathrm{NH} 3$ agricultural sources detected by IASI contributing to European spring haze episode: Agricultural NH3 Detected by IASI. Geophysical Research Letters 43, 5475-5482 (2016).

17. Petetin, H. et al. Assessing the ammonium nitrate formation regime in the Paris megacity and its representation in the CHIMERE model. Atmospheric Chemistry and Physics 16, 10419-10440 (2016).

18. Petit, J.-E. et al. Characterising an intense PM pollution episode in March 2015 in France from multisite approach and near real time data: Climatology, variabilities, geographical origins and model evaluation. Atmospheric Environment 155, 68-84 (2017).

19. Pay, M. T., Jiménez-Guerrero, P. \& Baldasano, J. M. Assessing sensitivity regimes of secondary inorganic aerosol formation in Europe with the CALIOPE-EU modeling system. Atmospheric Environment 51, 146-164 (2012). 
20. Ng, N. L. et al. Secondary organic aerosol formation from m-xylene, toluene, and benzene. Atmos. Chem. Phys. 14 (2007).

21. Zhang, Y. et al. Six-year source apportionment of submicron organic aerosols from near-continuous highly time-resolved measurements at SIRTA (Paris area, France). Atmos. Chem. Phys. 22 (2019).

22. Bruns, E. A. et al. Identification of significant precursor gases of secondary organic aerosols from residential wood combustion. Scientific Reports 6, (2016).

23. Srivastava, D. et al. Speciation of organic fractions does matter for aerosol source apportionment. Part 3: Combining off-line and on-line measurements. Science of The Total Environment 690, 944955 (2019).

24. Ng, N. L. et al. An aerosol chemical speciation monitor (ACSM) for routine monitoring of the composition and mass concentrations of ambient aerosol. Aerosol Science and Technology 45, 780-794 (2011).

25. Budisulistiorini, S. H. et al. Intercomparison of an Aerosol Chemical Speciation Monitor (ACSM) with ambient fine aerosol measurements in downtown Atlanta, Georgia. Atmospheric Measurement Techniques 7, 1929-1941 (2014).

26. Poulain, L. et al. Multi-year ACSM measurements at the central European research station Melpitz (Germany) - Part 1: Instrument robustness, quality assurance, and impact of upper size cutoff diameter. Atmos. Meas. Tech. 13, 4973-4994 (2020).

27. Middlebrook, A. M., Bahreini, R., Jimenez, J. L. \& Canagaratna, M. R. Evaluation of CompositionDependent Collection Efficiencies for the Aerodyne Aerosol Mass Spectrometer using Field Data. Aerosol Science and Technology 46, 258-271 (2012).

28. Crenn, V. et al. ACTRIS ACSM intercomparison - Part 1: Reproducibility of concentration and fragment results from 13 individual Quadrupole Aerosol Chemical Speciation Monitors (Q-ACSM) and consistency with co-located instruments. Atmospheric Measurement Techniques 8, 5063-5087 (2015).

29. Freney, E. et al. The second ACTRIS inter-comparison (2016) for Aerosol Chemical Speciation Monitors (ACSM): Calibration protocols and instrument performance evaluations. Aerosol Science and Technology 53, 830-842 (2019).

30. Weingartner, E. et al. Absorption of light by soot particles: determination of the absorption coefficient by means of aethalometers. Journal of Aerosol Science 34, 1445-1463 (2003).

31. Petit, J.-E. et al. Two years of near real-time chemical composition of submicron aerosols in the region of Paris using an Aerosol Chemical Speciation Monitor (ACSM) and a multi-wavelength Aethalometer. Atmospheric Chemistry and Physics 15, 2985-3005 (2015).

32. Drinovec, L. et al. The 'dual-spot' Aethalometer: an improved measurement of aerosol black carbon with real-time loading compensation. Atmospheric Measurement Techniques 8, 1965-1979 (2015).

33. Chiriaco, M. et al. ReOBS: a new approach to synthesize long-term multi-variable dataset and application to the SIRTA supersite. Earth Syst. Sci. Data 10, 919-940 (2018). 
34. Paatero, P. \& Tapper, U. Positive matrix factorization: A non-negative factor model with optimal utilization of error estimates of data values. Environmetrics 5, 111-126 (1994).

35. Canonaco, F., Slowik, J. G., Baltensperger, U. \& Prévôt, A. S. H. Seasonal differences in oxygenated organic aerosol composition: implications for emissions sources and factor analysis. Atmospheric Chemistry and Physics 15, 6993-7002 (2015).

36. Canonaco, F., Crippa, M., Slowik, J. G., Baltensperger, U. \& Prévôt, A. S. H. SoFi, an IGOR-based interface for the efficient use of the generalized multilinear engine (ME-2) for the source apportionment: ME-2 application to aerosol mass spectrometer data. Atmospheric Measurement Techniques 6, 3649-3661 (2013).

37. Canonaco, F. et al. A new method for long-term source apportionment with time-dependent factor profiles and uncertainty assessment using SoFi Pro: application to one year of organic aerosol data. Atmospheric Measurement Techniques Discussion (2020) doi:10.5194/amt-2020-204.

38. Aiken, A. C. et al. O/C and OM/OC ratios of primary, secondary, and ambient organic aerosols with high-resolution time-of-flight aerosol mass spectrometry. Environmental science \& technology 42, 4478-4485 (2008).

39. Kroll, J. H. et al. Carbon oxidation state as a metric for describing the chemistry of atmospheric organic aerosol. Nature Chemistry 3,133-139 (2011).

40. Canagaratna, M. R. et al. Elemental ratio measurements of organic compounds using aerosol mass spectrometry: characterization, improved calibration, and implications. Atmospheric Chemistry and Physics Discussions 14, 19791-19835 (2014).

41. Sandradewi, J. et al. Using Aerosol Light Absorption Measurements for the Quantitative Determination of Wood Burning and Traffic Emission Contributions to Particulate Matter. Environmental Science \& Technology 42, 3316-3323 (2008).

42. Zotter, P. et al. Evaluation of the absorption Ångström exponents for traffic and wood burning in the Aethalometer based source apportionment using radiocarbon measurements of ambient aerosol. Atmospheric Chemistry and Physics Discussions 1-29 (2016) doi:10.5194/acp-2016-621.

43. Petit, J.-E. et al. Submicron aerosol source apportionment of wintertime pollution in Paris, France by double positive matrix factorization (PMF2) using an aerosol chemical speciation monitor (ACSM) and a multi-wavelength Aethalometer. Atmospheric Chemistry and Physics 14, 13773-13787 (2014).

44. Lorenz, E. N. The predictability of a flow which possesses many scales of motion. Tellus 21, 289307 (1969).

45. Van Den Dool, H. M. Searching for analogues, how long must we wait? Tellus A 46, 314-324 (1994).

46. Zorita, E. \& Storch, H. V. The Analog Method as a Simple Statistical Downscaling Technique: Comparison with More Complicated Methods. JOURNAL OF CLIMATE 12, 16 (1999).

47. Cattiaux, J., Yiou, P. \& Vautard, R. Dynamics of future seasonal temperature trends and extremes in Europe: a multi-model analysis from CMIP3. Climate Dynamics 38, 1949-1964 (2012).

48. Kalnay, E. et al. The NCEP/NCAR 40-Year Reanalysis Project. Bulletin of the American Meteorological Society 77, 437-472 (1996). 
49. Raynaud, D. et al. Atmospheric analogues for physically consistent scenarios of surface weather in Europe and Maghreb: ATMOSPHERIC ANALOGUES FOR PHYSICALLY CONSISTENT SURFACE WEATHER. Int. J. Climatol. 37, 2160-2176 (2017).

50. Stein, A. F. et al. NOAA's HYSPLIT Atmospheric Transport and Dispersion Modeling System. Bulletin of the American Meteorological Society 96, 2059-2077 (2015).

51. Petit, J.-E., Favez, O., Albinet, A. \& Canonaco, F. A user-friendly tool for comprehensive evaluation of the geographical origins of atmospheric pollution: Wind and trajectory analyses. Environmental Modelling \& Software 88, 183-187 (2017).

\section{Figures}

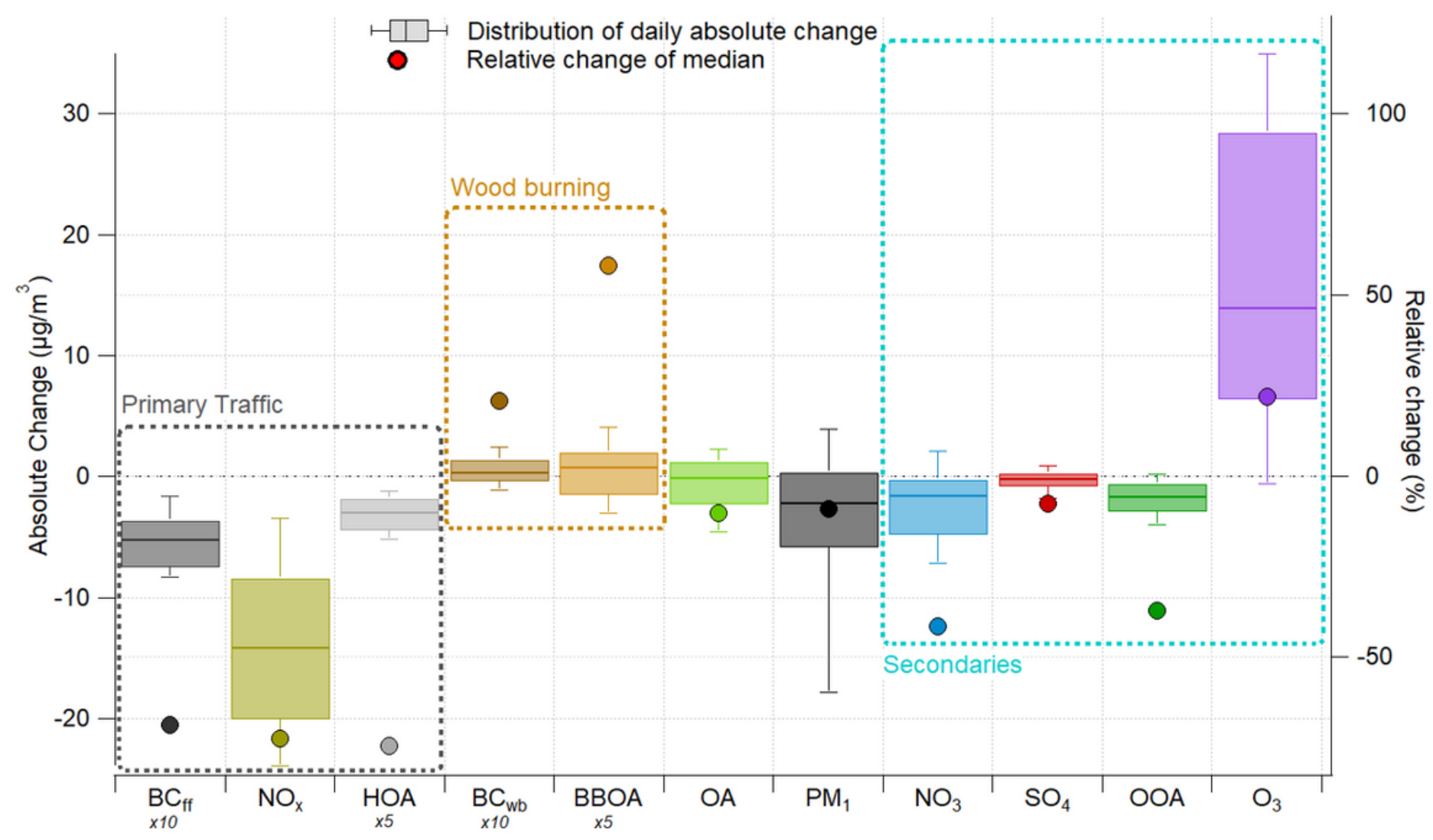

\section{Figure 1}

Absolute and relative changes of ambient concentrations of reactive gases and particulate pollutants due to lockdown. Left axis: Boxplots represent the distribution of daily absolute change $(\mu \mathrm{g} / \mathrm{m} 3) ; 10 \mathrm{th}$, 25 th, 50th, 75th and 90th percentiles were used. BCff, HOA, BCwb and BBOA concentration changes have been scaled for clarity (multiplicative factors are shown below variables). Right axis: Round markers refer to the relative change $(\%)$ of median concentrations. 

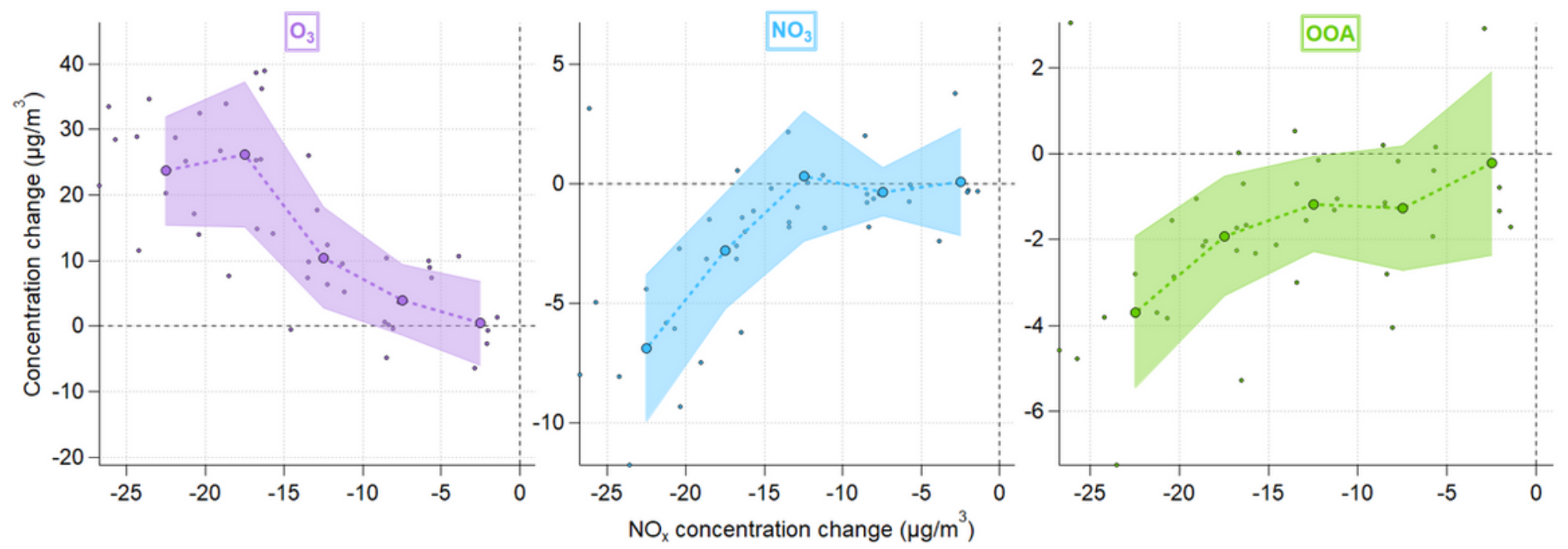

Figure 2

NOx dependence of $\mathrm{O} 3, \mathrm{NO} 3$ and OOA concentration changes. Concentration change $(\mu \mathrm{g} / \mathrm{m} 3)$ of $\mathrm{O} 3, \mathrm{NO} 3$ and OOA versus concentration changes of $\mathrm{NOx}(\mu \mathrm{g} / \mathrm{m} 3)$. Line and markers and shaded areas correspond to mean \pm standard deviation. 


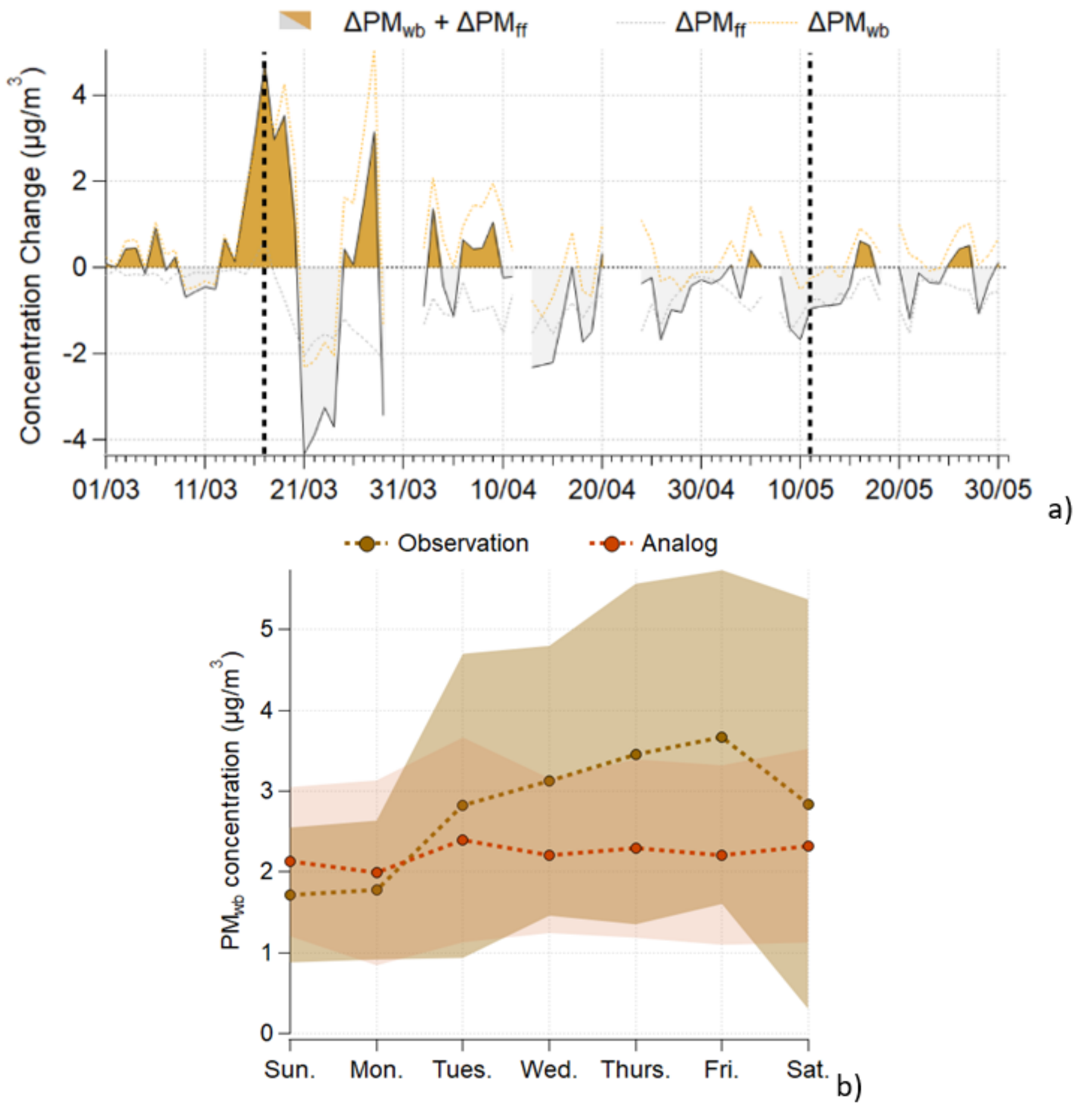

Figure 3

Impact of changes in wood burning concentrations during lockdown. a) Temporal variations of $\triangle P M w b+$ $\triangle \mathrm{PMff}$ during lockdown. Brown shaded area shows compensation of wood burning. Individual PMwb and PMff concentration change are also displayed with dotted lines. Black vertical lines delimit the start and the end of the lockdown period. b) Weekly variations of PMwb during lockdown (mean \pm standard deviation) for the observed (brown) and analog (dark red) dataset. 


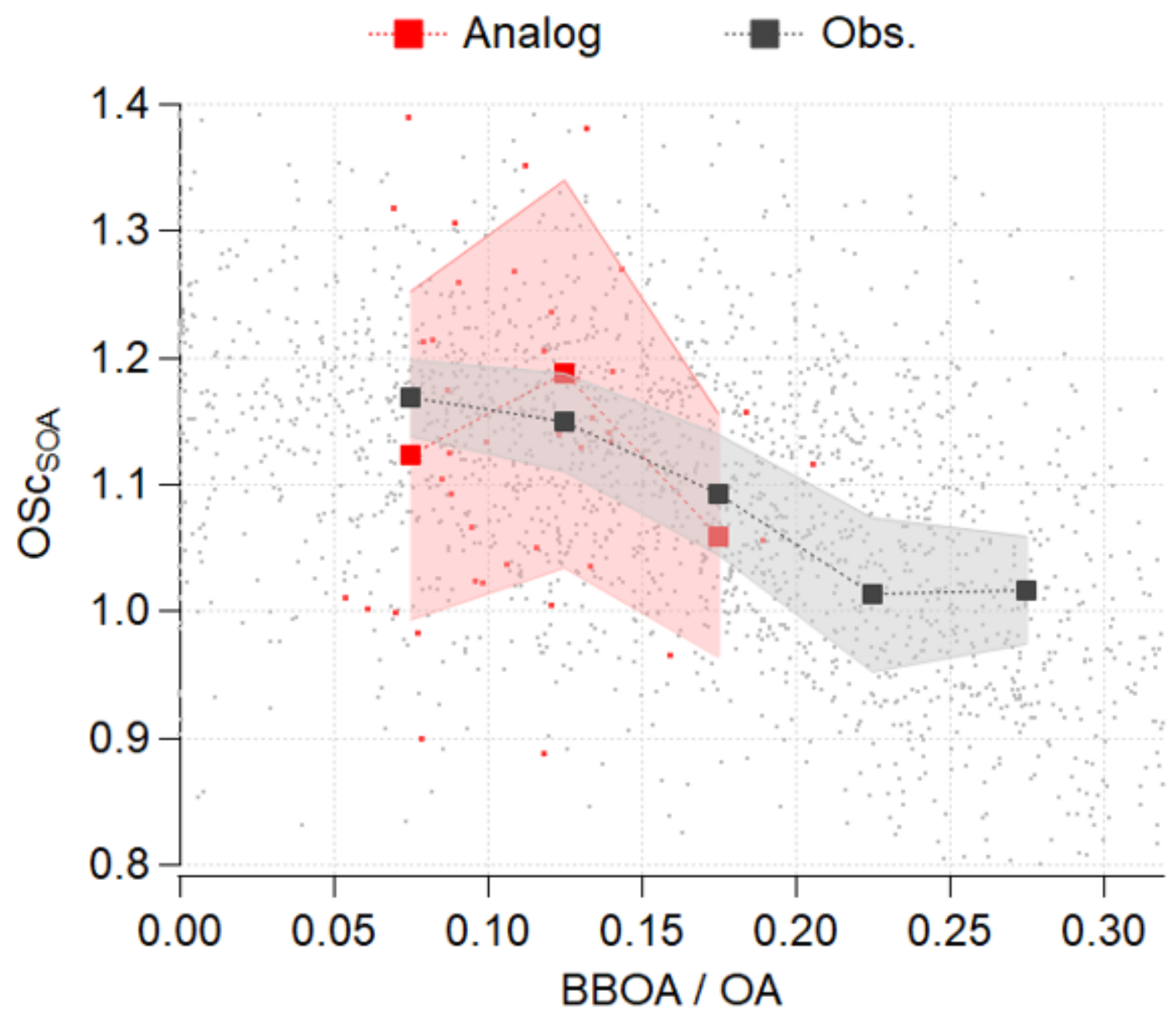

Figure 4

Impact of wood-burning contribution on the composition of SOA during lockdown. Scatter plot of the oxidation state of SOA (OScSOA) versus the fraction of BBOA in OA. Grey dots correspond to 30-min data; red dots to daily analog data. Lines and markers and shaded area represent mean \pm standard deviation of daily values for observations (grey) and analog (red).

\section{Supplementary Files}

This is a list of supplementary files associated with this preprint. Click to download.

- SupplementaryInformation.docx 